\title{
A REVIEW \\ Role of microsatellite markers in molecular diversity analysis of rice bean (Vigna umbellta)
}

\author{
Deepanshi Rathore, Monika, Monika Bajpai and Nidhi Varshney ${ }^{1}$ \\ Department of Biotechnology, Faculty of Life Sciences, Institute of Applied Medicines and Research, Ghaziabad, \\ (U.P.) India (Email: monisingh6666@gmail.com) \\ ${ }^{1}$ National Institute of Plant Genome Research, New Delhi, India \\ Email : deepanshi.rathore1996@gmail.com
}

Article Info : Received : 08.02.2020; Accepted : 28.03 .2020

Over the last few decades, the use of molecular markers has played very important role in rice breeding and genetics. Rice bean is a multipurpose, less utilized crop accepted to be tamed in the Myanmar-Thailand locale of Asia. It is believed to be a potential nutritive fodder legume. Among various types of molecular markers, microsatellites (SSRs) have been widely in used due to several advantages over other markers. These markers are appropriated all through the genome, high number of allelic variety at every locus, incredibly polymorphic just as being species-explicit and co-predominant; they have become an ever increasing number of critical hereditary markers in rice reproducing programmes. In spite of the fact that there has been next to no exploration or exceptionally less distributed writing on rice bean with respect to its genetic diversity, the aim of this review is to summarize the current knowledge concerning the linkage of microsatellite markers to rice bean which is regarded as minor food and is mainly grown for human consumption, though it is additionally utilized for roughage and green manure. Rice bean has an ability to give balance diet to the domesticated animals and to continue under wide scope of climatic condition in any case, more spotlight is required on this harvest for greater prominence as a potential vegetable yield.

Key words : Rice bean, Molecular markers, Microsatellite markers (SSR), Molecular diversity

How to cite this paper : Rathore, Deepanshi, Monika, Bajpai, Monika and Varshney, Nidhi (2020). Role of microsatellite markers in molecular diversity analysis of rice bean (Vigna umbellta). Asian J. Bio. Sci., 15 (1) : 15-20.DOI : 10.15740/HAS/AJBS/15.1/15-20. Copyright@ 2020: Hind Agri-Horticultural Society. 